\title{
Mice endometrium receptivity in early pregnancy is impaired by maternal hyperinsulinemia
}

\author{
RUNQIN LI ${ }^{1}$, JUAN WU ${ }^{1,3}$, JUNLIN HE ${ }^{1}$, YINGXIONG WANG ${ }^{1}$, XUEQING LIU $^{1}$, XUEMEI CHEN ${ }^{1}$, \\ $\mathrm{CHAO}_{\text {TONG }}^{2}$, YUBIN DING ${ }^{1}$, YAN SU ${ }^{1}$, WENQI CHEN ${ }^{1}, \mathrm{CHEN} \mathrm{ZHANG}^{1}$ and RUFEI GAO ${ }^{1}$ \\ ${ }^{1}$ Laboratory of Reproductive Biology, School of Public Health, Chongqing Medical University; \\ ${ }^{2}$ Department of Obstetrics, The First Affiliated Hospital of Chongqing Medical University, \\ Chongqing 400016; ${ }^{3}$ Childen's Hospital of Chongqing Medical University, Chongqing 400014, P.R. China
}

Received February 2, 2016; Accepted February 7, 2017

DOI: $10.3892 / \mathrm{mmr} .2017 .6322$

\begin{abstract}
Previous studies have investigated the lower embryo implantation rates in women with polycystic ovary syndrome, obesity and type 2 diabetes, and specifically the association between the abnormal oocyte and embryo and hyperinsulinemia. The importance of hyperinsulinemia on maternal endometrium receptivity remains to be elucidated. The present study used a hyperinsulinemic mouse model to determine whether hyperinsulinemia may affect endometrial receptivity. An insulin intervention mouse model was first established. The serum levels of insulin, progesterone and estradiol were subsequently detected by ELISA assay analysis. The number of implantation sites was recorded using Trypan blue dye and the morphology of mice uteri was investigated using hematoxylin and eosin staining. The expression levels of molecular markers associated with endometrial receptivity were detected by reverse transcription-quantitative polymerase chain reaction, western blotting and immunohistochemistry analyses. Finally, the importance of mechanistic target of rapamycin (mTOR) expression following insulin treatment was determined. Mice treated with insulin developed insulin resistance and hyperinsulinemia. The number of implantation sites following insulin treatment did not differ between the control and insulin-treated groups. Additionally, no significant morphological alterations in mice uteri between control and insulin-treated groups were observed. However, the expression levels of estrogen receptor (Esr) 1, Esr2, progesterone receptor and homeobox A10 associated with endometrial receptivity, were imbalanced during endometrium receptivity when
\end{abstract}

Correspondence to: Dr Rufei Gao or Professor Yingxiong Wang, Laboratory of Reproductive Biology, School of Public Health, Chongqing Medical University, Box 197, 1 Yixueyuan Road, Chongqing 400016, P.R. China

E-mail: gao_ru_fei@163.com

E-mail:wyx61221@aliyun.com

Key words: endometrium receptivity, embryo implantation, insulin, hyperinsulinemia, insulin resistance maternal hyperinsulinemia was induced. Western blot analysis revealed that expression levels of endometrial phosphorylated (p)-mTOR and p-ribosomal protein S6 kinase $\beta-1$ were significantly greater in the insulin-treated group. These results demonstrated that although an embryo may implant into endometrium, mice endometrium receptivity in early pregnancy may be impaired by maternal hyperinsulinemia. In addition, mTOR signaling may be involved in this process. The present study provides preliminary results demonstrating that female reproduction may be compromised during hyperinsulinemia, which requires further investigation in future studies.

\section{Introduction}

Embryo implantation, a key part of early pregnancy, is a complex reproductive process. Disruption of embryo implantation may lead to a miscarriage. During implantation, the endometrium undergoes morphological and physiological alterations to become receptive to the embryo and permit its invasion (1). In addition to conceptus quality, the establishment of uterine receptivity is necessary for successful embryo implantation. It has been reported that worldwide $\sim 10-15 \%$ of couples experience infertility during their reproductive years, which is primarily associated with implantation failure (2). Previous studies have identified compromised reproduction in women with polycystic ovary syndrome (PCOS), obesity and type 2 diabetes, which includes impaired oocyte and embryo quality, lower fertilization rates, decreased embryo implantation rates and elevated risk of spontaneous loss of pregnancy following in vitro fertilization (3-7). However, the underlying molecular mechanisms remain to be elucidated.

Insulin is a protein hormone secreted by pancreatic $\beta$ cells that consist of A- and B-polypeptide chains, which are linked by disulfide bonds. Insulin promotes the uptake and utilization of glucose, and inhibits glycogenolysis and gluconeogenesis. Therefore, it is extensively involved in the metabolism of glucose, fat and protein (8). Hyperinsulinemia and insulin resistance are established characteristics of women with PCOS, obesity and type 2 diabetes $(9,10)$. Previous studies have explored the direct role and underlying mechanisms of abnormal oocyte and embryo development and hyperinsulinemia during lower embryo implantation in women 
with PCOS, obesity and type 2 diabetes $(11,12)$. However, the importance of hyperinsulinemia and insulin resistance in the maternal endometrium remains to be elucidated. The insulin receptor has been previously demonstrated to exhibit significantly altered expression patterns in the menstrual cycle (13). Insulin receptor expression was observed to be present primarily in the secretory phase and localized at the stromal cells whereas its expression was downregulated from follicular to luteal phases (13). In addition, insulin regulated-mTOR signaling is important for lipid and glucose metabolism in skeletal muscle and liver (14-17), and a previous study revealed that mTOR was essential for endometrial receptivity (18). These results demonstrated that insulin may serve an important function in the endometria. Although, a previous clinical study revealed the reduced expression of markers for endometrial receptivity in PCOS patients (19), to the best of our knowledge there is a current lack of evidence to confirm the abnormal expression of endometrial receptivity markers resulting from hyperinsulinemia and insulin resistance.

It is possible that hyperinsulinemia and insulin resistance may be responsible for reduced endometrial receptivity in hyperinsulinemic and insulin-resistant females. Therefore, the aim of the present study was to generate a hyperinsulinemic and insulin-resistant mouse model in order to determine whether hyperinsulinemia may affect endometrial receptivity.

\section{Materials and methods}

Establishment of mouse model. A total of 100 Kunming female mice (weight, $22 \pm 1.8 \mathrm{~g}$; age, 6 weeks) were used to generate this animal model. Ethical approval for the use of animals in this study was obtained from Chongqing Medical University (Chongqing, China). Care and handling of these mice was conducted in accordance with the animal research committee guidelines established by the Ethics Committee of the Institute of Zoology, Chongqing Medical University. An insulin intervention mouse model was established as previously described by $\mathrm{Ou}$ et al (11). Mice were randomly divided into control and insulin-treated groups ( $\mathrm{n}=50 /$ group). The treatment protocol was composed of 2 subcutaneous injections of saline for the control group or insulin for insulin-treated group, in order to induce hyperinsulinemia. Human recombinant insulin (Insulin glargine) was purchased from Sanofi (Shanghai, China). For the insulin-treated group, 0.05 IU insulin was injected until day 16, and from day 17 on it was gradually increased until reaching $0.8 \mathrm{IU} /$ day by day $23(20,21)$ (day 17, $0.2 \mathrm{IU}$; day 18, $0.35 \mathrm{IU}$; day 19, $0.5 \mathrm{IU}$; day 20, $0.65 \mathrm{IU}$; day 21, $0.8 \mathrm{IU}$; day 22, $0.8 \mathrm{IU}$; day 23, $0.8 \mathrm{IU})$. All mice were then mated with fertile males (female: male, 2:1) overnight and the female mice were checked for vaginal plugs the following morning. The day at which a positive vaginal plug was identified was considered to be day 1 (D1) of pregnancy.

Detection of serum insulin, progesterone (P4), estradiol (E2) levels and plasma glucose levels. Blood samples $(\sim 1 \mathrm{ml})$ were collected from the eye socket on insulin treated day 23 and incubated at room temperature for $3 \mathrm{~h}$ to obtain the serum. The serum levels of insulin, P4 and E2 were detected using enzyme-linked immunosorbent assay kits (YH1332, YH4016 and YH3997; Shanghai Yan Hui Biological Technology, Co., Ltd., Shanghai, China) according to the manufacturer's protocol. Absorbance was read at $450 \mathrm{~nm}$. An ACCU-CHEK Advantage blood glucose meter (Roche Applied Science, Mannheim, Germany) was used to determine the glucose concentrations in the blood, which were taken from the cut tail tip. Homeostasis model assessment (HOMA) were calculated as: Plasma glucose level x serum insulin level/22.5.

Quantification of implantation sites and collection of endometrial tissue. In order to examine attachment and implantation, pregnant dams were sacrificed by cervical dislocation on D5 and following Trypan blue $(10 \mathrm{mg} / \mathrm{ml})$ injection into the tail veins (22). The number of implantation sites was identified by distinct blue bands. In addition, endometrial tissues at D4-D6 were collected and squeezed from the uterine horns by the use of fine forceps under an anatomical microscope (23). The isolated endometrial tissues were immediately stored in liquid nitrogen.

Reverse transcription-quantitative polymerase chain reaction. TRIzol reagent (Takara Biotechnology Co., Ltd., Dalian, China) was used for total RNA extraction from $50 \mathrm{mg}$ endometrium obtained from D4-D6, according to the manufacturer's protocol. RNA concentration and purity was determined by spectrophotometric determination of $\mathrm{OD}_{260 / 280}$ ratio. Total RNA $(0.5 \mathrm{mg})$ was used for cDNA synthesis in a $10 \mathrm{ml}$ reaction system using the PrimeScript $\mathrm{RT}$ reagent kits (Takara Biotechnology Co., Ltd.). The specific primers for estrogen receptor (Esr) 1, Esr2, progesterone receptor (Pgr), homeobox A10 (Hoxa10) and $\beta$-actin are presented in Table I. qPCR was performed using the CFX96 Real-Time PCR Detection system (Bio-Rad Laboratories, Inc., Hercules, CA, USA) and SYBR Premix Ex Taq (Takara Biotechnology Co., Ltd.). The reaction mixture consisted of $12.5 \mu 1 \mathrm{SYBR}$ Premix Ex Taq (2X), $0.5 \mu \mathrm{l}$ of each specific primer $(10 \mu \mathrm{M})$ and $2 \mu \mathrm{l}$ cDNA. Water was then added to a final volume of $25 \mu \mathrm{l}$. Following initial denaturation at $95^{\circ} \mathrm{C}$ for $30 \mathrm{sec}$, PCR was performed for 40 cycles according to the following parameters: Denaturation at $95^{\circ} \mathrm{C}$ for $10 \mathrm{sec}$; annealing and extension at $60^{\circ} \mathrm{C}$ for $30 \mathrm{sec}$. Experiments were performed in triplicate for each sample. Gene expression was obtained by normalizing cDNA quantity to that of $\beta$-actin and calculated using the $2^{-\Delta \Delta \mathrm{Cq}}$ method (24).

Western blot analysis. Proteins were extracted from $200 \mathrm{mg}$ endometrium obtained from D4-D6 mice. Endometrial tissues were lysed using RIPA lysis buffer (Beyotime Institute of Biotechnology, Jiangsu, China). The concentration of protein was determined using a bicinchoninic acid protein assay kit (Beyotime Institute of Biotechnology). Proteins were boiled in 5X SDS sample loading buffer for a minimum of $10 \mathrm{~min}$ and subsequently stored at $-80^{\circ} \mathrm{C}$ prior to use. $50 \mu \mathrm{g}$ proteins were separated on $10 \%$ SDS-PAGE gels. Proteins were then transferred onto polyvinylidene difluoride membranes (Bio-Rad Laboratories, Inc.). Membranes were subsequently blocked with 5\% non-fat milk at room temperature, before they were incubated with rabbit monoclonal anti-Hoxa10 (SC17159; 1:500; Santa Cruz Biotechnology, Inc., Dallas, TX, USA), mouse monoclonal anti-Esr1 (ab66102; 1:1,000; 
Table I. Primer sequences used for reverse transcription-quantitative polymerase chain reaction.

\begin{tabular}{lll}
\hline Gene & \multicolumn{1}{c}{ Forward primer $\left(5^{\prime}-3^{\prime}\right)$} & \multicolumn{1}{c}{ Reverse primer $\left(5^{\prime}-3^{\prime}\right)$} \\
\hline Esr 1 & CACCAGATCCAAGGGAA & CGGCGTTGAACTCGTAG \\
Esr2 & GACTGTAGAACGGTGTGGTCATCAA & CTGTGAGGTAGGAATGCGAAAC \\
Pgr & GCCTATACCGATCTCCCTG & TTCCCTATGAGTGGCTTCTAC \\
Hoxa10 & AACGCTGCCCTTACACGA & GTGGACGCTACGGCTGAT \\
-actin & CCTGAGGCTCTTTTCCAGCC & TAGAGGTCTTTACGGATGTCAACGT
\end{tabular}

Esr1/2, estrogen receptor 1/2; Pgr, progesterone receptor; Hoxa10, homeobox A10.

Table II. Effect of chronic insulin treatment on maternal weight, metabolic parameters and serum hormone levels.

\begin{tabular}{lcc}
\hline & \multicolumn{2}{c}{ Group } \\
\cline { 2 - 3 } Parameter & Control & Insulin-treated \\
\hline Number of mice & 50 & 50 \\
Body weight $(\mathrm{g})$ & $38.7 \pm 2.30$ & $34.46 \pm 1.21^{\mathrm{a}}$ \\
Plasma glucose (mM/l) & $7.14 \pm 1.05$ & $9.62 \pm 0.50^{\mathrm{a}}$ \\
Serum insulin (mU/1) & $16.57 \pm 0.74$ & $26.77 \pm 1.17^{\mathrm{a}}$ \\
HOMA (glucose x insulin/22.5) & $5.25 \pm 0.71$ & $11.43 \pm 0.22^{\mathrm{a}}$ \\
E2 (pg/ml) & $57.15 \pm 4.40$ & $32.52 \pm 1.76^{\mathrm{a}}$ \\
P4 (pg/ml) & $6.51 \pm 0.24$ & $9.56 \pm 0.28^{\mathrm{a}}$ \\
\hline
\end{tabular}

Data are presented as the mean \pm standard deviation. Experiments were performed in triplicate for each sample. ${ }^{\mathrm{a}} \mathrm{P}<0.05 \mathrm{vs}$. control. HOMA, homeostasis model assessment; E2, estradiol; P4; progesterone.

Abcam, Cambridge, UK), mouse monoclonal anti-Pgr (ab2765; 1:500; Abcam), mouse monoclonal anti-Esr2 (ab288; 1:1,000; Abcam), rabbit monoclonal anti-mechanistic target of rapamycin (mTOR; 2983; 1:500; Cell Signaling Technology, Inc., Danvers, MA, USA), rabbit monoclonal anti-phosphorylated (p)-mTOR (5536; 1:500; Cell Signaling Technology, Inc.), rabbit monoclonal anti-ribosomal protein S6 kinase $\beta-1$ (p70S6K; 2708; 1:1,000; Cell Signaling Technology, Inc.), rabbit monoclonal anti-p-p70S6K (9234; 1:500; Cell Signaling Technology, Inc.) and mouse monoclonal anti- $\beta$-actin (A5441; 1:1,500; Sigma-Aldrich; Merck KGaA, Darmstadt, Germany) overnight at $4^{\circ} \mathrm{C}$. The membranes were washed 3 times with Tris-buffered saline containing Tween-20 (0.2\%), and then incubated for $1 \mathrm{~h}$ on room temperature with a horseradish peroxidase (HRP)-conjugated secondary antibody (TA130003 and TA130023; 1:1,000; OriGene Technologies, Inc., Beijing, China). The positive bands were detected using HRP-enhanced chemiluminescence reagents (WBKLS0500; Merck KGaA) and quantified by densitometry analysis using Quantity One software version 4.6.2 (Bio-Rad Laboratories, Inc.). Protein expression was normalized to $\beta$-actin.

Hematoxylin and eosin $(H \& E)$ staining. H\&E staining was performed according to the manufacturer's protocol (Nanjing Jiancheng Bioengineering Institute, Nanjing, China). Briefly, sections ( $4 \mu \mathrm{m}$ in thickness) of uterine tissue sacrificed on D5 were deparaffinized in xylene and rehydrated in decreasing concentrations of ethanol. Subsequently, the sections were stained with hematoxylin $(0.45 \%)$ for $3 \mathrm{~min}$ and with eosin (1\%) for $30 \mathrm{sec}$ at room temperature, followed by dehydration until they were cleared. Finally, the tissue sections were mounted with neutral gum.

Immunohistochemistry. Mice uteri at D5 were fixed in 4\% paraformaldehyde and embedded in paraffin. The tissue was then cut to $5 \mu \mathrm{m}$ sections. Immunohistochemistry was performed using DAB color reagent kit (SP-9000; Zhongshan Biosciences Inc. China) according to the manufacturer's protocols. The sections were examined and imaged under a microscope (BX43, Olympus Corporation, Tokyo, Japan). Non-immune goat serum (Zhongshan Biosciences Inc. China) was used instead of the primary antibody as a negative control.

Statistical analysis. All experiments were repeated at least three times. The data were analyzed using SPSS software (version, 16.0; SPSS Inc., Chicago, IL, USA). The Student's $t$-test was used to determine the differences in serum insulin, P4 and E2 levels, mRNA and protein expression levels and the number of implantation sites between the control and insulin-treated groups. $\mathrm{P}<0.05$ was considered to indicate a statistically significant difference.

\section{Results}

Levels of insulin, E2 and P4 in serum. In order to determine the effects of maternal insulin resistance on embryo implantation, a mouse model of hyperinsulinemia was established through exogenous insulin injection $(11,21)$. The effects of chronic treatment with insulin on mouse weight, and the serum levels of insulin, E2 and P4 are presented in Table II. In addition, serum glucose levels and the HOMA values were significantly higher in the insulin-treated group. The results demonstrated that the insulin-treated group developed chronic insulin resistance and hyperinsulinemia.

Number of implantation sites on D5. A previous study demonstrated that endometrial receptivity is maintained on day 5 of pregnancy in mice (25). In order to determine the potential role of hyperinsulinemia on endometrium receptivity, the present study recorded the number of embryo implantation sites on 
D5 by counting the distinctive blue bands on the mice uteri as a result of Trypan blue staining. No significant difference between the number of implantation sites in the insulin-treated group was observed when compared with the control group (Fig. 1A). In addition, no alterations in the morphology of the uteri between the two groups were observed (Fig. 1B).

Endometrium receptivity is impaired by maternal hyperinsulinemia. Although no significant difference was evident between the two groups when examined visually, it was unclear whether endometrium receptivity was altered at the microscopic scale. In order to investigate this further, morphological examination of uterine cross-sections was performed at D5, and no marked difference between the control and insulin-treated groups was observed (Fig. 2). During the implantation window, the process of embryo implantation is divided into the following three steps: Pre-implantation on day 4 , peri-implantation on day 5 and post-implantation on day 6 of gestation in mice $(26,27)$. The expression levels of molecules associated with endometrial receptivity, such as Esr1 and Pgr may vary, depending on their functions during the different steps of the embryo implantation process. The present study determined that expression levels of Esr1, Pgr and Hoxa10 were significantly upregulated $(\mathrm{P}<0.05$, Fig. 3$)$ and Esr2 levels were downregulated in the insulin-treated group when compared with the control group on D4 ( $\mathrm{P}<0.05$, Fig. 3). However, no obvious differences in Pgr expression levels were observed during peri-implantation on D5 (Fig. 3). Unlike Pgr, Esr1, Esr2 and Hoxa10 were significantly imbalanced in mice with hyperinsulinemia ( $\mathrm{P}<0.05$; Fig. $3 \mathrm{~B}$, D and $\mathrm{E})$. In addition, a marked reduction in the levels of these molecules was recorded during post-implantation on D6 of gestation in mice (Fig. 3C and D). Therefore, it is possible that the establishment process of endometrium receptivity was altered by maternal hyperinsulinemia, even though the embryo was able to implant into endometrium.

mTOR may be responsible for altered endometrial receptivity by maternal hyperinsulinemia. A previous study revealed that mTOR was essential for endometrial receptivity (18), and previous studies have demonstrated that insulin could serve its roles though mTOR $(28,29)$. Therefore, the present study investigated mTOR signaling in the endometrium following insulin treatment. During the implantation window, the vital time for endometrial receptivity, western blotting of endometrial tissues revealed a significant increase in endometrial p-mTOR and p-p70S6K protein expression levels in the insulin-treated group when compared with the control group ( $\mathrm{P}<0.05$; Fig. 4). No marked difference in the levels of total mTOR and p70S6K protein expression levels was identified in the insulin-treated group when compared with the control group (Fig. 4).

\section{Discussion}

Previous clinical studies have identified compromised reproduction in women with PCOS, obesity and type 2 diabetes $(30,31)$. Hyperinsulinemia and insulin resistance are established characteristics of women with PCOS, obesity and type 2 diabetes $(32,33)$. Previous studies have investigated lower embryo implantation rates in females with these
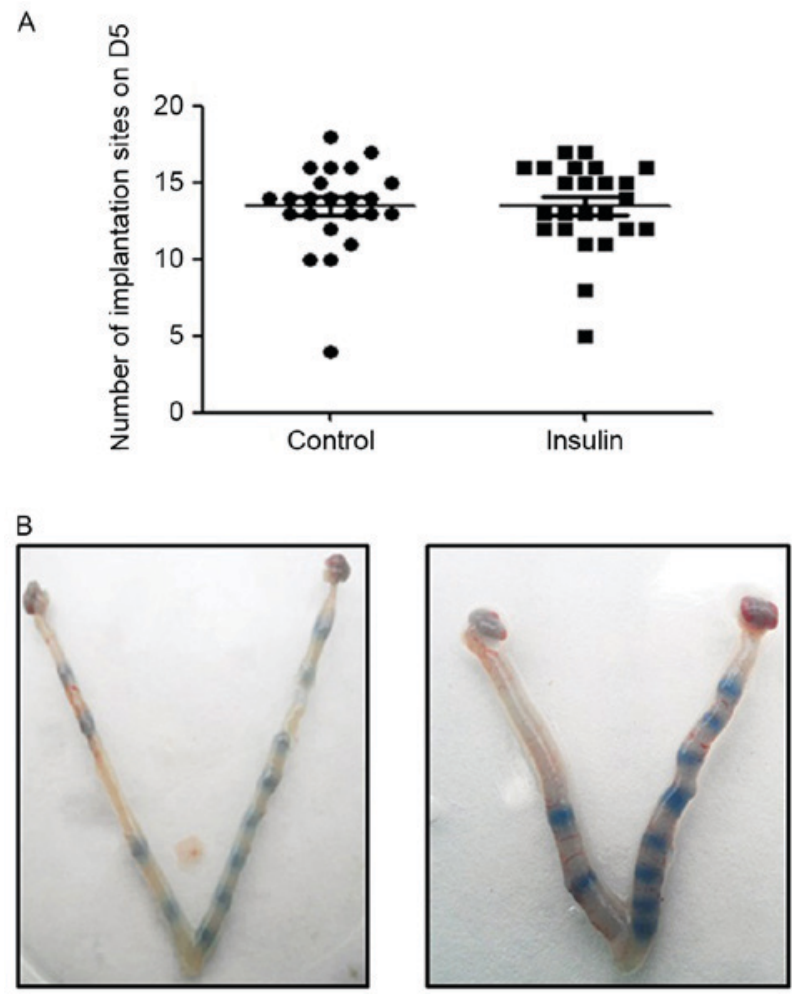

Figure 1. Number of implantation sites at D5 in insulin-treated and control mice. (A) Trypan blue was injected on D5 and the number of implantation sites as indicated by distinct blue bands was recorded. (B) Morphology of the uteri of pregnant mice at D5. Left image are the uteri from control mice and the right image are the uteri from insulin-treated mice. D5, day 5 of pregnancy.

conditions, and an association between abnormal oocyte and embryo development and hyperinsulinemia $(11,12)$. However, the importance of hyperinsulinemia and insulin resistance on maternal endometrium remains to be elucidated. The present study determined that mice endometrium receptivity in early pregnancy was affected by maternal hyperinsulinemia.

During early pregnancy, the establishment of uterine receptivity is necessary for successful embryo implantation. Uterine receptivity is established and maintained through a series of specific cellular and molecular events (34). However, in the event that the genes associated with the establishment of uterine receptivity are expressed abnormally, embryo implantation may be affected directly and lead to spontaneous abortion (35). In the animal model developed in the present study, the number of implantation sites at D5 was not significantly different following treatment with insulin. These results may be due to the short duration of insulin treatment. Females with PCOS, obesity and type 2 diabetes are exposed to hyperinsulinemia and insulin resistance for a long period of time. The present study determined that although the embryo was able to implant into endometrium, the genes associated with uterine receptivity, including Esr1, Pgr, Hoxa10 and Esr2 were dysregulated in mice with maternal hyperinsulinemia. Therefore, it is possible that the process of endometrium receptivity establishment was altered by maternal hyperinsulinemia. Although the present study did not investigate the effect of hyperinsulinemia on endometrium function following embryo implantation into the uterus, 

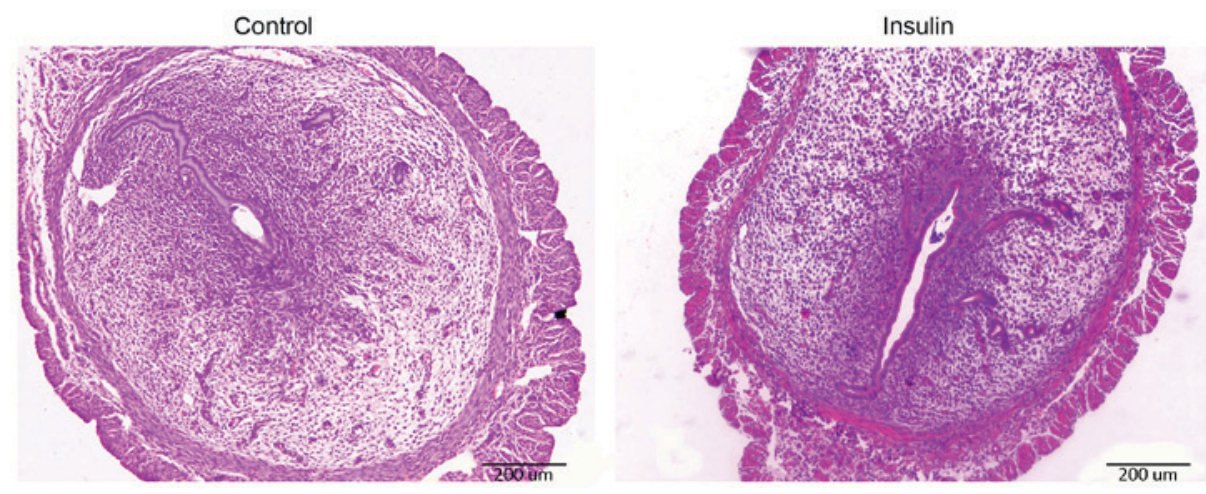

Figure 2. Implantation sites on D5 of pregnancy from control and insulin-treated mice were stained with hematoxylin and eosin (scale bar, $200 \mu \mathrm{m}$ ). No obvious morphological alterations between the two groups were identified.

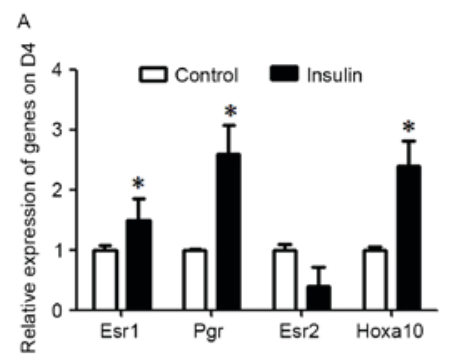

B
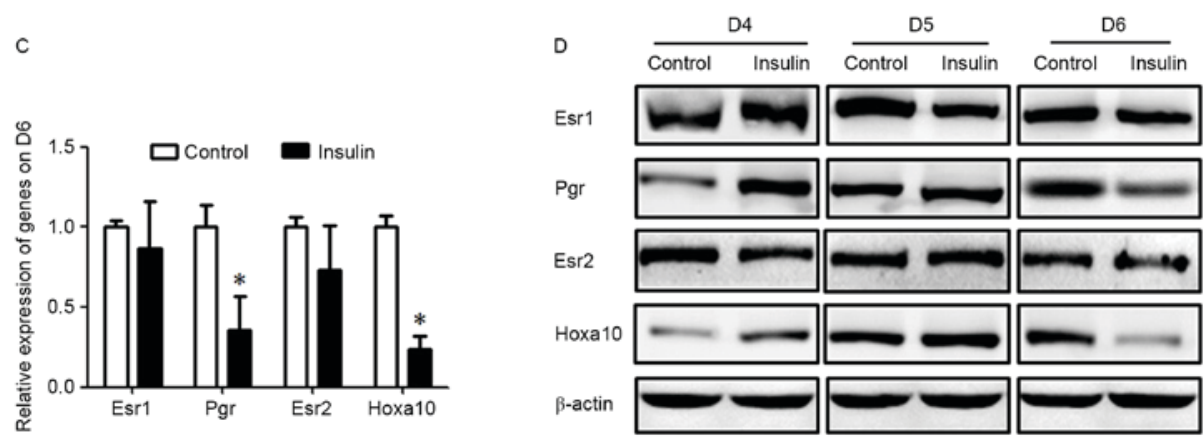

E
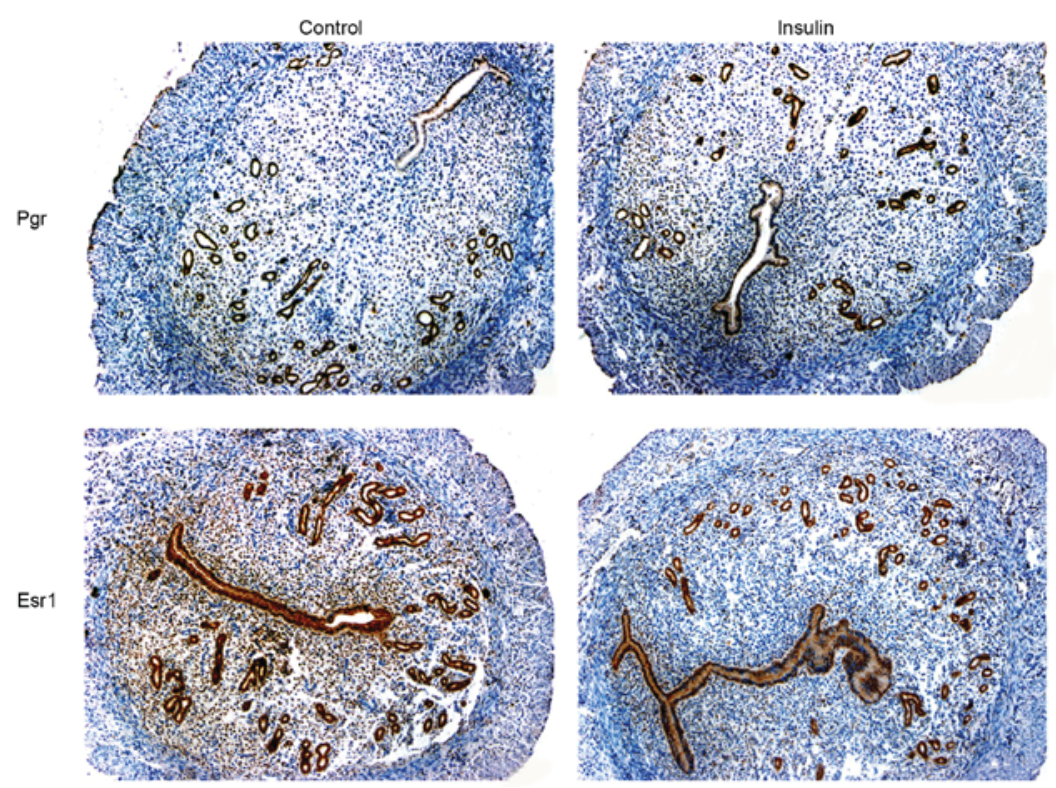

Figure 3. Expression of genes associated with endometrial receptivity during the embryo implantation window. Reverse transcription-quantitative polymerase chain reaction was performed to compare the mRNA expression levels of Esr1, Esr2, Pgr and Hoxa10 in the endometrium between control and insulin-treated groups at (A) D4, (B) D5 and (C) D6. Data are presented as the mean \pm standard error ( $\mathrm{n}=6$ ). ${ }^{*} \mathrm{P}<0.05$ vs. control. (D) Western blot analysis of markers for endometrial receptivity during the embryo implantation window. (E) The location of Pgr and Esrl protein markers for endometrial receptivity on D5 as determined by immunohistochemical staining (scale bar, $200 \mu \mathrm{m}$ ). Esr1/2, estrogen receptor 1/2; Pgr, progesterone receptor; Hoxa10, homeobox A10; D4-6, days 4-6 of pregnancy. 
A

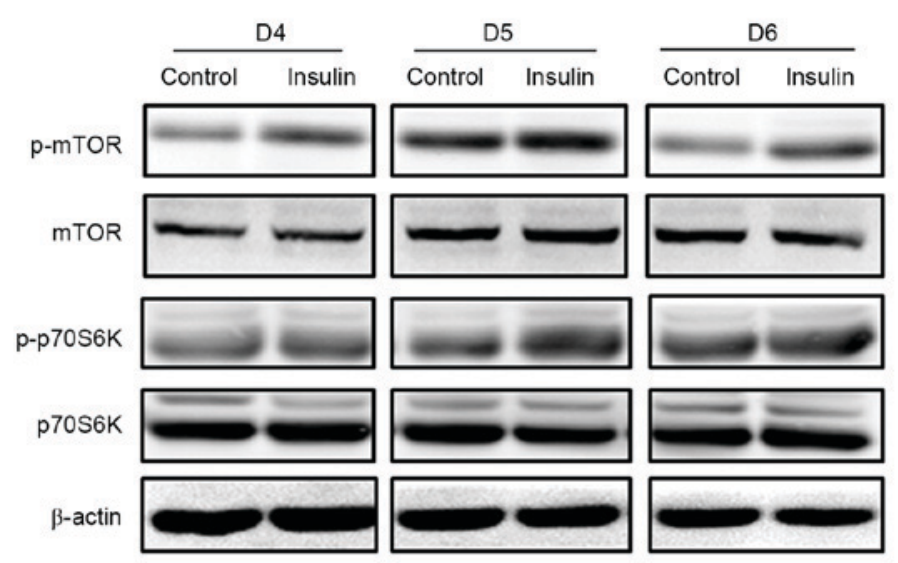

B
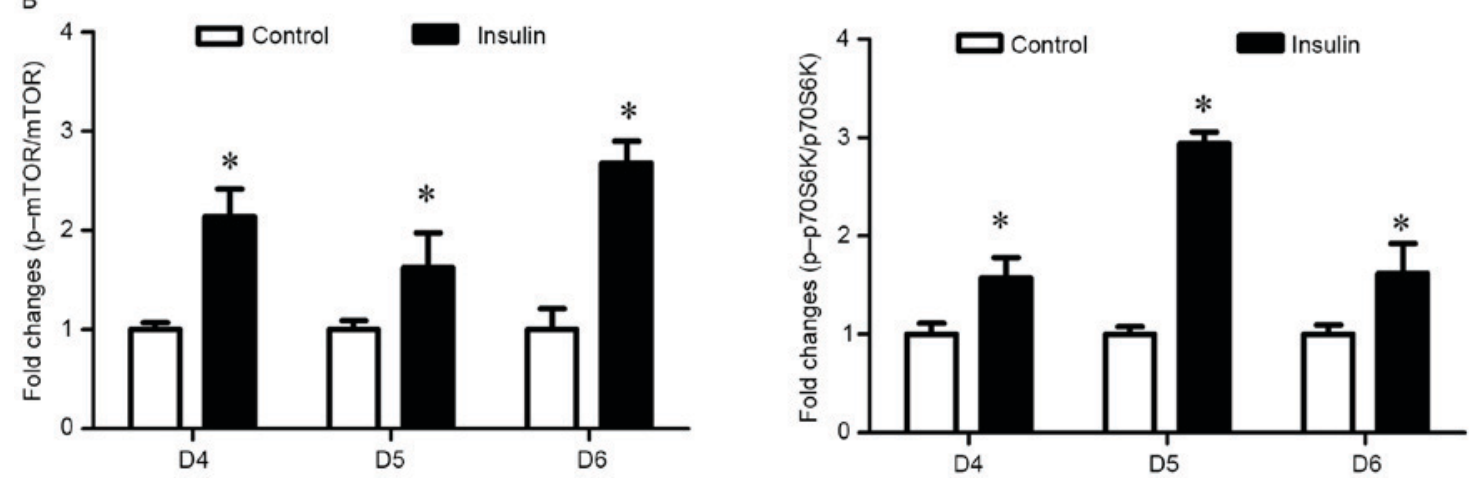

Figure 4. Endometrial mTOR signaling was altered during the embryo implantation window by maternal hyperinsulinemia. (A) An increase in the phosphorylation of mTOR and p70S6K following insulin treatment was determined using western blotting. (B) Quantification of protein expression levels. Data are presented as the mean \pm standard error $(n=3)$. "P<0.05 vs. control. D4-6, day 4-6 of pregnancy. mTOR, mechanistic target of rapamycin; $p$-mTOR, phosphorylated mTOR; p70S6K, ribosomal protein S6 kinase $\beta$-1; p-p70S6K, phosphorylated-p70S6K.

a previous study determined that abnormal endometrium receptivity may increase the risk of abnormal decidualization and placentation in the later stages of pregnancy and lead to a miscarriage (34).

mTOR is a member of the phosphatidylinositol 3-kinase-associated kinase superfamily. It is a core component of raptor-mTOR (mTORC1) and rictor-mTOR (mTORC2) complexes that control various cellular processes. mTORC1 and mTORC2 regulate several elements downstream of the type I insulin-like growth factor receptor and insulin receptor (36). mTOR serves a crucial role in mammalian growth control as an important molecule of signal transduction, including cell proliferation, growth, differentiation and apoptosis (37-40). Insulin could serve its roles though mTOR $(28,29)$. Neil et al determined that insulin may induce activation of mTOR signaling in glioblastoma cells (41). Fritzen et al observed that mTOR signaling via unc-51 like autophagy activating kinase 1 may mediate the autophagy-inhibiting effect of insulin in human skeletal muscle (42). In addition, previous studies have determined that mTOR was essential for early mouse embryo growth and proliferation of embryonic stem cells (43-45). Furthermore, the importance of mTOR in uterine tissues has been verified in various studies (46-48). A previous study demonstrated that endometrial receptivity was compromised by the intrauterine injection with rapamycin (18), which is an inhibitor of mTOR. In the present study, a significant increase in endometrial p-mTOR and p-p70S6K protein expression was detected in the insulin-treated group. Therefore, mTOR signaling may contribute to impaired endometrium receptivity during maternal hyperinsulinemia and insulin resistance. However, future intervention studies are required in order for these results to be confirmed.

In conclusion, the present study determined that the effect of maternal hyperinsulinemia on endometrium receptivity may be important for embryo implantation. Although an embryo may implant into endometrium, mice endometrium receptivity in early pregnancy may be affected by maternal hyperinsulinemia. In addition, mTOR signaling may be involved in this process. The underlying molecular mechanisms involving mTOR require further investigation. The present study provided vital preliminary data for future investigation of compromised reproduction in women with hyperinsulinemia.

\section{Acknowledgements}

The present study was supported by the National Natural Science foundation of China (grant no. 81300486 and 81300678), the Natural Science Foundation of Chongqing (grant no. cstc2015jcyjA10013), the Scientific Research Program of Science and the Technology Commission of Yuzhong District of Chongqing (grant no. 20150104). 


\section{References}

1. Nagashima T, Li Q, Clementi C, Lydon JP, DeMayo FJ and Matzuk MM: BMPR2 is required for postimplantation uterine function and pregnancy maintenance. J Clin Invest 123: 2539-2550, 2013.

2. Mori M, Kitazume M, Ose R, Kurokawa J, Koga K, Osuga Y, Arai S and Miyazaki T: Death effector domain-containing protein (DEDD) is required for uterine decidualization during early pregnancy in mice. J Clin Invest 121: 318-327, 2011.

3. Dale PO, Tanbo T, Haug E and Abyholm T: The impact of insulin resistance on the outcome of ovulation induction with low-dose follicle stimulating hormone in women with polycystic ovary syndrome. Hum Reprod 13: 567-570, 1998.

4. Svendsen PF, Nilas L, Nørgaard K, Jensen JE and Madsbad S: Obesity, body composition and metabolic disturbances in polycystic ovary syndrome. Hum Reprod 23: 2113-2121, 2008.

5. Igosheva N, Abramov AY, Poston L, Eckert JJ, Fleming TP, Duchen MR and McConnell J: Maternal diet-induced obesity alters mitochondrial activity and redox status in mouse oocytes and zygotes. PLoS One 5: e10074, 2010.

6. Lintsen AM, Pasker-de Jong PC, de Boer EJ, Burger CW Jansen CA, Braat DD and van Leeuwen FE: Effects of subfertility cause, smoking and body weight on the success rate of IVF. Hum Reprod 20: 1867-1875, 2005.

7. Cano F, García-Velasco JA, Millet A, Remohí J, Simón C and Pellicer A: Oocyte quality in polycystic ovaries revisited Identification of a particular subgroup of women. J Assist Reprod Genet 14: 254-261, 1997.

8. Steiner DF, Park SY, Støy J, Philipson LH and Bell GI: A brief perspective on insulin production. Diabetes Obes Metab 11 (Suppl 4): 189-196, 2009.

9. Homburg R: Should patients with polycystic ovarian syndrome be treated with metformin? A note of cautious optimism. Hum Reprod 17: 853-856, 2002.

10. Kasumov T, Solomon TP, Hwang C, Huang H, Haus JM, Zhang R and Kirwan JP: Improved insulin sensitivity after exercise training is linked to reduced plasma C14: 0 ceramide in obesity and type 2 diabetes. Obesity (Silver Spring) 23 1414-1421, 2015.

11. Ou XH, Li S, Wang ZB, Li M, Quan S, Xing F, Guo L, Chao SB, Chen Z, Liang XW, et al: Maternal insulin resistance causes oxidative stress and mitochondrial dysfunction in mouse oocytes. Hum Reprod 27: 2130-2145, 2012

12. Schulte MM, Tsai JH and Moley KH: Obesity and PCOS: The effect of metabolic derangements on endometrial receptivity at the time of implantation. Reprod Sci 22: 6-141, 2015.

13. Mioni R, Mozzanega B, Granzotto M, Pierobon A, Zuliani L, Maffei P, Blandamura S, Grassi S, Sicolo N and Vettor R: Insulin receptor and glucose transporters mRNA expression throughout the menstrual cycle in human endometrium: A physiological and cyclical condition of tissue insulin resistance. Gynecol Endocrinol 28: 1014-1018, 2012.

14. Williamson DL, Dungan CM, Mahmoud AM, Mey JT, Blackburn BK and Haus JM: Aberrant REDD1-mTORC1 responses to insulin in skeletal muscle from Type 2 diabetics. Am J Physiol Regul Integr Comp Physiol 309: R855-R863, 2015.

15. Caron A, Richard D and Laplante M: The Roles of mTOR complexes in lipid metabolism. Annu Rev Nutr 35: 321-348, 2015

16. Sharawy MH, El-Awady MS, Megahed N and Gameil NM: Attenuation of insulin resistance in rats by agmatine: Role of SREBP-1c, mTOR and GLUT-2. Naunyn Schmiedebergs Arch Pharmacol 389: 45-56, 2016

17. Xiao F, Yu J, Guo Y, Deng J, Li K, Du Y, Chen S, Zhu J, Sheng H and Guo F: Effects of individual branched-chain amino acids deprivation on insulin sensitivity and glucose metabolism in mice. Metabolism 63: 841-850, 2014.

18. Chen X, He J, Ding Y, Zeng L, Gao R, Cheng S, Liu X and Wang Y: The role of MTOR in mouse uterus during embryo implantation. Reproduction 138: 351-356, 2009.

19. Wang A, Ji L, Shang W, Li M, Chen L, White RE and Han G: Expression of GPR30, ER $\alpha$ and ER $\beta$ in endometrium during window of implantation in patients with polycystic ovary syndrome: A pilot study. Gynecol Endocrinol 27: 251-255, 2011.

20. Poretsky L, Clemons J and Bogovich K: Hyperinsulinemia and human chorionic gonadotropin synergistically promote the growth of ovarian follicular cysts in rats. Metabolism 41: 903-910, 1992
21. Lima MH, Souza LC, Caperuto LC, Bevilacqua E, Gasparetti AL, Zanuto R, Saad MJ and Carvalho CR: Up-regulation of the phosphatidylinositol 3-kinase/protein kinase B pathway in the ovary of rats by chronic treatment with hCG and insulin. J Endocrinol 190: 451-459, 2006

22. Paria BC, Huet-Hudson YM and Dey SK: Blastocyst's state of activity determines the 'window' of implantation in the receptive mouse uterus. Proc Natl Acad Sci USA 90: 10159-10162, 1993.

23. Tan Y, Tan D, He M, Gu M, Wang Z, Zeng G and Duan E: A model for implantation: Coculture of blastocysts and uterine endometrium in mice. Biol Reprod 72: 556-561, 2005.

24. Livak KJ and Schmittgen TD: Analysis of relative gene expression data using real-time quantitative PCR and the 2(-Delta Delta C(T)) method. Methods 25: 402-408, 2001.

25. Zorn TM, Soto-Suazo M, Pellegrini CR, Oliveira JG and Stumpf WE: Estradiol receptor binding to the epithelium of uterine lumen and glands: Region- and time-related changes during preimplantation and periimplantation periods studied by autoradiography. Histochem Cell Biol 120: 1-12, 2003.

26. Liu G, Zhang X, Lin H, Wang H, Li Q, Ni J and Zhu C: Effects of E-cadherin on mouse embryo implantation and expression of matrix metalloproteinase-2 and -9 . Biochem Biophys Res Commun 343: 832-838, 2006.

27. Chan SY: Effects of prostaglandin E2 and F2 alpha on peri-implantation development of mouse embryos in vitro. Prostaglandins 42: 321-336, 1991.

28. Palaniappan M, Menon B and Menon KM: Stimulatory effect of insulin on theca-interstitial cell proliferation and cell cycle regulatory proteins through MTORC1 dependent pathway. Mol Cell Endocrinol 366: 81-89, 2013.

29. Li Z, Miard S, Laplante M, Sonenberg N and Picard F: Insulin stimulates IGFBP-2 expression in 3T3-L1 adipocytes through the PI3K/mTOR pathway. Mol Cell Endocrinol 358: 63-68, 2012.

30. Catalano PM and Shankar K: Obesity and pregnancy: Mechanisms of short term and long term adverse consequences for mother and child. BMJ 356: j1, 2017.

31. Moran L and Teede $\mathrm{H}$ : Metabolic features of the reproductive phenotypes of polycystic ovary syndrome. Hum Reprod Update 15: 477-488, 2009.

32. Diamanti-Kandarakis E and Dunaif A: Insulin resistance and the polycystic ovary syndrome revisited: An update on mechanisms and implications. Endocr Rev 33: 981-1030, 2012.

33. Templeman NM, Skovs $\varnothing$ S, Page MM, Lim GE and Johnson JD: A causal role for hyperinsulinemia in obesity. J Endocrinol 232: R173-R183, 2017.

34. Wang H and Dey SK: Roadmap to embryo implantation: Clues from mouse models. Nat Rev Genet 7: 185-199, 2006.

35. Quenby S, Anim-Somuah M, Kalumbi C, Farquharson R and Aplin JD: Different types of recurrent miscarriage are associated with varying patterns of adhesion molecule expression in endometrium. Reprod Biomed Online 14: 224-234, 2007.

36. Sabatini DM: mTOR and cancer: Insights into a complex relationship. Nat Rev Cancer 6: 729-734, 2006.

37. Vahidnezhad H, Youssefian L and Uitto J: Molecular genetics of the PI3K-AKT-mTOR pathway in genodermatoses: Diagnostic implications and treatment opportunities. J Invest Dermatol 136: $15-23,2016$.

38. Wataya-Kaneda M: Mammalian target of rapamycin and tuberous sclerosis complex. J Dermatol Sci 79: 93-100, 2015.

39. Somers MJ and Paul E: Safety considerations of mammalian target of rapamycin inhibitors in tuberous sclerosis complex and renal transplantation. J Clin Pharmacol 55: 368-376, 2015.

40. Huo F, Zhang C, He H and Wang Y: MicroRNA-144-3p inhibits proliferation and induces apoptosis of human salivary adenoid carcinoma cells via targeting of mTOR. Biotechnol Lett 38: 409-416, 2016.

41. Neil J, Shannon C, Mohan A, Laurent D, Murali R and Jhanwar-Uniyal M: ATP-site binding inhibitor effectively targets mTORC1 and mTORC2 complexes in glioblastoma. Int J Oncol 48: 1045-1052, 2016.

42. Fritzen AM, Madsen AB, Kleinert M, Treebak JT, Lundsgaard AM, Jensen TE, Richter EA, Wojtaszewski J, Kiens B and Frøsig C: Regulation of autophagy in human skeletal muscle: Effects of exercise, exercise training and insulin stimulation. J Physiol 594: 745-761, 2016.

43. Martin PM and Sutherland AE: Exogenous amino acids regulate trophectoderm differentiation in the mouse blastocyst through an mTOR-dependent pathway. Dev Biol 240: 182-193, 2001. 
44. Gangloff YG, Mueller M, Dann SG, Svoboda P, Sticker M Spetz JF, Um SH, Brown EJ, Cereghini S, Thomas G and Kozma SC: Disruption of the mouse mTOR gene leads to early postimplantation lethality and prohibits embryonic stem cell development. Mol Cell Biol 24: 9508-9516, 2004.

45. Kim J, Song G, Wu G, Gao H, Johnson GA and Bazer FW: Arginine, leucine, and glutamine stimulate proliferation of porcine trophectoderm cells through the MTOR-RPS6K-RPS6-EIF4EBP1 signal transduction pathway. Biol Reprod 88: 113, 2013.

46. Wollenhaupt K, Brüssow KP, Albrecht D and Tomek W: The $\mathrm{Akt} / \mathrm{mTor}$ signaling cascade is modified during placentation in the porcine uterine tissue. Reprod Biol 13: 184-194, 2013.
47. Mahdi H, Xiu J, Reddy SK and DeBernardo R: Alteration in $\mathrm{PI} 3 \mathrm{~K} / \mathrm{mTOR}$, MAPK pathways and Her2 expression/amplification is more frequent in uterine serous carcinoma than ovarian serous carcinoma. J Surg Oncol 112: 188-194, 2015.

48. Guntas G, Hallett RA,Zimmerman SP, Williams T, Yumerefendi H, Bear JE and Kuhlman B: Engineering an improved light-induced dimer (iLID) for controlling the localization and activity of signaling proteins. Proc Natl Acad Sci USA 112: 112-117, 2015. 